\title{
User acceptance of information technology: system characteristics, user perceptions and behavioral impacts
}

\author{
Fred D. Davis \\ University of Michigan, Business School, Ann Arbor, MI 48109, USA
}

(Received 7 May 1991 and accepted in revised form 8 December 1991)

\begin{abstract}
Lack of user acceptance has long been an impediment to the success of new information systems. The present research addresses why users accept or reject information systems and how user acceptance is affected by system design features. The technology acceptance model (TAM) specifies the causal relationships between system design features, perceived usefulness, perceived ease of use, attitude toward using, and actual usage behavior. Attitude theory from psychology provides the rationale for hypothesized model relationships, and validated measures were used to operationalize model variables. A field study of 112 users regarding two end-user systems was conducted to test the hypothesized model. TAM fully mediated the effects of system characteristics on usage behavior, accounting for $36 \%$ of the variance in usage. Perhaps the most striking finding was that perceived usefulness was $50 \%$ more influential than ease of use in determining usage, underscoring the importance of incorporating the appropriate functional capabilities in new systems. Overall, TAM provides an informative representation of the mechanisms by which design choices influence user acceptance, and should therefore be helpful in applied contexts for forecasting and evaluating user acceptance of information technology. Implications for future research and practice are discussed.
\end{abstract}

\section{Introduction}

Lack of user acceptance has long been an impediment to the success of new information systems (Gould, Boies \& Lewis, 1991; McCarroll, 1991; Nickerson, 1981). The goal of most organizationally based information systems is to improve performance on the job. Unfortunately, performance impacts are lost whenever systems are rejected by users. User acceptance is often the pivotal factor determining the success or failure of an information system project. The present research uses the technology acceptance model (TAM) to address why users accept or reject information technology and how user acceptance is influenced by system characteristics. From a practical standpoint, we are interested not only in explaining why a system is unacceptable to a set of users, but also in understanding how to improve user acceptance through the design of the system. The choice of functional and interface characteristics of a new system are largely under the control of information systems designers, developers, selectors and managers. Needed is a model of how such design choices affect user acceptance in the workplace.

The proposed TAM is shown in Figure 1. A prospective user's overall attitude toward using a given system is hypothesized to be a major determinant of whether 


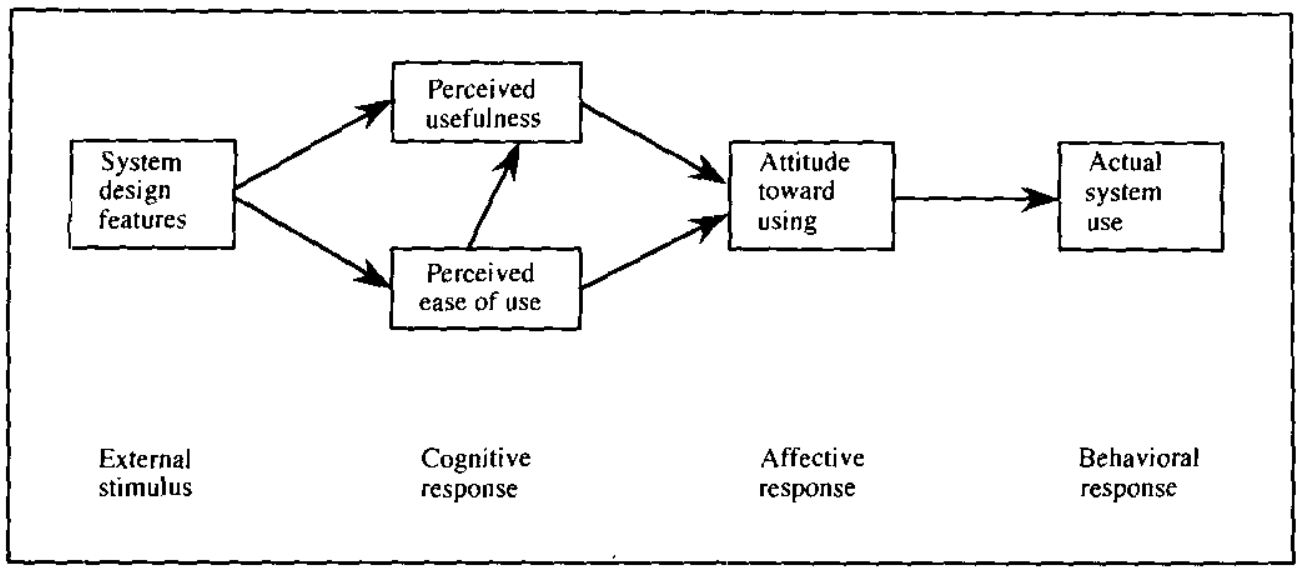

FIGURE 1. Technology acceptance model.

or not he or she actually uses it. Attitude toward using, in turn, is a function of two beliefs: perceived usefulness and perceived ease of use. Perceived ease of use has a causal effect on perceived usefulness. System design features directly influence perceived usefulness and perceived ease of use. System design features have an indirect effect on attitude toward using and actual usage behavior through their direct effect on perceived usefulness and perceived ease of use.

\section{Theory}

The technology acceptance model is based on principles adopted from Fishbein and Ajzen's (1975) attitude paradigm from psychology, which (1) specifies how to measure the behavior-relevant components of attitudes, (2) distinguishes between beliefs and attitudes and (3) specifies how external stimuli, such as the objective features of an attitude object, are causally linked to beliefs, attitudes and behavior. Fishbein and Ajzen $(1975 ;$ p. 31) draw the distinction between two attitude constructs: attitude toward the object $\left(A_{O}\right)$, which refers to a person's affective evaluation of a specified attitude object, and attitude toward the behavior $\left(A_{B}\right)$, which refers to a person's evaluation of a specified behavior involving the object. It has been shown that $A_{B}$ relates more strongly to a specified behavior than does $A_{O}$ (Ajzen \& Fishbein, 1977). Hence, within the proposed technology acceptance model (TAM), attitude toward using the system will be employed. Adapting the general $A_{B}$ definition, attitude toward using is defined as "the degree of evaluative affect that an individual associates with using the target system in his or her job." The present research employs Fishbein and Ajzen's recommended attitude measurement scales to operationalize attitude toward using (e.g. Ajzen \& Fishbein, 1980: Appendix A; see also Fishbein \& Ajzen, 1975; Chapters 3 and 4). The standard measures employ seven-point rating scales anchored with evaluative semantic differential adjective pairs (such as "good-bad"), and typically possess high reliability and validity.

Fishbein and Ajzen (1975) draw the distinction between beliefs and attitudes, a distinction which has frequently been overlooked in MIS attitude research (Swanson, 1982). Whereas a person's belief about a behavior (also called a perceived 
consequence of the behavior) refers to his or her subjective likelihood that performing the behavior will lead to a specified outcome (Fishbein \& Ajzen, 1975; p. 233), attitude toward the behavior is an affective evaluation of the behavior. According to Fishbein and Ajzen (1975; p. 233) attitude toward a behavior is determined by an expectancy-value model of beliefs $\left(b_{i}\right)$ weighted by evaluations of the consequences $\left(e_{i}\right)$ :

$$
A_{B}=\sum_{i=1, n} b_{i} e_{i}
$$

Although Fishbein and Ajzen recommend using a self-stated evaluation term, this has become a point of considerable debate in psychology. First, multiplying two variables together to form an index assumes they're both scaled at the ratio level of measurement. However, psychological ratings such as $b_{i}$ and $e_{i}$ generally only achieve the interval level of measurement (Hauser \& Shugan, 1980). The multiplication of interval-scaled measures introduces systematic error of unknown magnitude into the resulting product term (Schmidt, 1973). Second, using hierarchical regression to circumvent the ratio-scaling problem, expectancy-value theorists have observed that the people often do not combine expectancies and values multiplicatively (Bagozzi, 1984; Stahl \& Harrell, 1981). Moreover, statistically estimated (e.g. via regression) weights often predict as well as or better than their self-stated counterparts (Shoemaker \& Waid, 1982), and provide a representative picture of the cognitive activity underlying judgmental processes (Einhorn, Kleinmuntz \& Kleinmuntz, 1979), while avoiding the ratio-scaling problem discussed above. Therefore, TAM employs statistically estimated as opposed to self-stated value weights.

By identifying the particular beliefs that are operative in the context of computer user behavior, the proposed model should provide diagnostic insight into how system characteristics influence user attitudes and usage. Two specific beliefs, perceived usefulness and perceived ease of use, have been identified as important user acceptance criteria by previous research (Davis, 1989; Goodwin, 1987; Gould et al., 1991; Hill, Smith \& Mann, 1987). Perceived usefulness is defined as "the degree to which an individual believes that using a particular system would enhance his or her job performance." Perceived ease of use is defined as "the degree to which an individual believes that using a particular system would be free of physical and mental effort." Two factor analyses reported by Davis (1989) suggest that perceived ease of use and perceived usefulness are statistically distinct constructs.

Perceived ease of use is hypothesized to have a significant direct effect on perceived usefulness. Between two systems that perform the identical set of functions, a user should find the one that is easier to use more useful. A designer should therefore be able to enhance perceived usefulness either by adding new functional capabilities to a system, or by making it easier to invoke the functions which already exist. Given that some fraction of a user's total job content is devoted to physically using the system per se, if the user becomes more productive in that fraction of his or her job via greater ease of use, then he or she should become more productive overall. Perceived usefulness is not hypothesized to have an impact on perceived ease of use. Perceived usefulness concerns the expected overall impact of system use on job performance (process and outcome), whereas ease of use pertains only to those performance impacts related to the process of using the system per se. 
Hence, the performance impacts concerning ease of use are a logical subset of those comprising usefulness. Making a system easier to use, all else held constant, should make the system more useful. The converse does not hold, however. Consider a hypothetical new forecasting model which, although equally easy to use as the model it supersedes, provides a more accurate forecast. Moving from the old model to the new one, usefulness goes up with no effect on ease of use. Thus, ease of use influences usefulness but not vice versa.

Academics and practitioners alike aim to better understand how to choose from among the multitude of possibilities afforded by information technology those particular design features that will contribute most to user acceptance and performance (e.g. Goslar, 1986; Klein \& Beck, 1987; Reimann \& Waren, 1985). According to Fishbein and Ajzen (1975: p. 396), external stimuli influence a person's attitude toward a behavior indirectly by influencing his or her salient beliefs about the consequences of performing the behavior. Since system design features are external stimuli, they should influence beliefs about using a system. In summary, attitude theory from psychology provides a rationale for the flow of causality from system design features through perceptions to attitude and finally to usage.

\section{Hypotheses}

The technology acceptance model is expressed by the following structural equations (Duncan, 1975):

$$
\begin{aligned}
\mathrm{EOU} & =\beta_{11} \text { System }+e_{1} \\
\mathrm{USEF} & =\beta_{21} \text { System }+\beta_{22} \mathrm{EOU}+e_{2} \\
\mathrm{ATT} & =\beta_{31} \mathrm{EOU}+\beta_{32} \mathrm{USEF}+e_{3} \\
\mathrm{USE} & =\beta_{41} \mathrm{ATT}+e_{4}
\end{aligned}
$$

While "System" is a dummy variable taking on value 0 for electronic mail and 1 for the text editor, USE refers to intensity of system usage, ATT refers to attitude toward using, USEF refers to perceived usefulness and EOU refers to perceived ease of use. Ordinary least-squares regression is used to test this structural equation model (Land, 1973). The statistical significance of the proposed TAM relationships, expressed in hypotheses $1-5$ below, will be assessed using the $t$-statistic corresponding to each estimated parameter.

H1: Attitude toward using will have a significant positive effect on actual system use.

H2: Perceived usefulness will have a significant positive effect on attitude toward using, controlling for perceived ease of use.

H3: Perceived ease of use will have a significant positive effect on attitude toward using, controlling for perceived usefulness.

H4: Perceived ease of use will have a significant positive effect on perceived usefulness, controlling for system.

H5: System will have a significant effect on perceived usefulness and perceived ease of use. 
The data will also be used to test whether the causal relationships implicitly hypothesized to be indirect have no significant direct effect. These tests are expressed in hypotheses 6 and 7 below. Hierarchical regression and associated $F$-tests of the significance of the increase in $R^{2}$ due to the additional variables will be used for these hypotheses.

H6: Perceived usefulness, perceived ease of use, and system will not have significant direct effects on actual system use, controlling for attitude toward using.

H7: System will not have a significant direct effect on attitude toward using, controlling for perceived usefulness and perceived ease of use.

In addition to testing for the significance vs. non-significance of the hypothesized relationships, the data will also be used to estimate the magnitudes of the causal parameters. The estimates will be the standardized regression coefficients, expressed both as point and confidence interval estimates.

\section{Method}

\section{SUBJECTS AND PROCEDURE}

Subjects were 112 professional and managerial employees of a large North American corporation. A questionnaire was circulated to 120 users asking them to rate two different software systems, an electronic mail system and a text editor, which are widely available in their organization. One hundred and twelve responses by the following day yielded a response rate of $93 \cdot 3 \%$.

\section{QUESTIONNAIRE}

The questionnaire first screened respondents to make sure thay had previously used the target electronic mail system and text editor, so that the attitudes and beliefs measured were formed based on direct behavioral experience with the attitude object (Fazio \& Zanna, 1981). Instructions in the questionnaire asked subjects not to fill out the section regarding a given system if they haven't used it. Of the 112 participants, 109 completed the section of the questionnaire pertaining to electronic mail and 76 completed the section pertaining to the editor. For each system, respondents were asked to rate their perceived ease of use (EOU), perceived usefulness (USEF), attitude toward using (ATT) and actual current use of the system (USE).

Attitude toward using was measured using five standard 7-point semantic differential rating scales as suggested by Ajzen and Fishbein (1980) for operationalizing attitudes toward behaviors: "All things considered, my using electronic mail in my job is: Good-Bad; Wise-Foolish; Favorable-Unfavorable; Beneficial-Harmful; and Positive-Negative" on a seven point scale with midpoint labeled "Neutral." This attitude scale had a Cronbach alpha reliability of 0.96 in the present sample. 
Perceived ease of use and perceived usefulness were measured using the measurement scales given in the Appendix, which were developed and shown to have a high degree of convergent and discriminant validity by Davis (1989). In the present sample, the scales were highly reliable, with Cronbach alpha coefficients of 0.97 for perceived usefulness and 0.91 for perceived ease of use.

Two items were used to measure self-reported system use. The first one, a measure of the frequency of use of the system, read as follows: "On the average, I use electronic mail (pick most accurate answer): Don't use at all; Use less than once a week; Use about once each week; Use several times each week; Use about once each day, Use several times each day." The second usage measure asked subjects to specify how many hours they normally spend each week using the target system. Frequency of use and amount of time spent using a target system are typical of the usage metrics employed in MIS research (e.g. Ginzberg, 1981; Robey, 1979). Available evidence suggests that such self-reported time estimates, although not necessarily precise in an absolute sense, are accurate as relative indicants of the amount of time spent on job activities (Hartley et al., 1977). Given that the methodologies applied to the data require measures scaled at no more than the interval level of measurement, the self-reported items should be adequate. The hours-per-week question exhibited a right-skewed distribution of responses, and was rescaled by taking logarithms to make the distribution more symmetric. A linear transformation was then performed on the rescaled hours per week question to give it the same range as the frequency of use question. Averaging the use items yielded a reliability of $0 \cdot 70$.

\section{Results}

Following Duncan (1975) and Land (1973), regression analyses were performed on data pooled across the two target systems $(n=185)$. Table 1 contains the results of OLS regressions applied to the hypothesized equations of the model. Table 2

TABLE 1

$T A M$ regression tests

\begin{tabular}{|c|c|c|c|c|c|c|c|}
\hline $\begin{array}{l}\text { Dependent } \\
\text { variable }\end{array}$ & $R^{2}$ & $\begin{array}{l}\text { Independent } \\
\text { variable }\end{array}$ & $b$ & S.E. $(b)$ & $\beta$ & $t$-statistic & $\begin{array}{c}\text { Significant } \\
\text { level }\end{array}$ \\
\hline \multirow[t]{2}{*}{ EOU } & \multirow[t]{2}{*}{0.044} & Constant & $3 \cdot 323$ & $0 \cdot 155$ & & 21.463 & 0.000 \\
\hline & & System & -0.581 & $0 \cdot 201$ & -0.210 & -0.289 & $0 \cdot 004$ \\
\hline \multirow[t]{3}{*}{ USEF } & \multirow[t]{3}{*}{0.400} & Constant & 0.933 & $0 \cdot 214$ & & 4.356 & 0.000 \\
\hline & & System & -0.036 & $0 \cdot 151$ & $-0 \cdot 014$ & -0.238 & $0 \cdot 812$ \\
\hline & & EOU & 0.591 & 0.055 & 0.630 & $10 \cdot 661$ & $0 \cdot 000$ \\
\hline \multirow[t]{3}{*}{ ATT } & \multirow[t]{3}{*}{0.550} & Constant & $0 \cdot 224$ & $0 \cdot 134$ & & 1.668 & $0 \cdot 097$ \\
\hline & & EOU & $0 \cdot 100$ & 0.049 & $0 \cdot 134$ & $2 \cdot 037$ & $0 \cdot 043$ \\
\hline & & USEF & 0.531 & 0.054 & $0 \cdot 650$ & 9.893 & $0 \cdot 000$ \\
\hline \multirow[t]{2}{*}{ USE } & \multirow[t]{2}{*}{$0 \cdot 308$} & Constant & $4 \cdot 192$ & $0 \cdot 283$ & & 14.802 & $0 \cdot 000$ \\
\hline & & ATT & $0 \cdot 220$ & 0.025 & 0.555 & 8.792 & 0.000 \\
\hline \multirow{3}{*}{$\begin{array}{l}\text { USE } \\
\text { (w/USEF } \\
\text { included) }\end{array}$} & \multirow[t]{3}{*}{0.361} & Constant & 3.411 & 0.323 & & $10 \cdot 565$ & 0.000 \\
\hline & & USEF & 0.077 & 0.016 & 0.435 & 4.913 & 0.000 \\
\hline & & ATT & 0.089 & 0.039 & $0 \cdot 205$ & $2 \cdot 316$ & 0.022 \\
\hline
\end{tabular}


TABLE 2

Hierarchical regression tests of indirect relationships

\begin{tabular}{|c|c|c|c|c|c|c|c|}
\hline $\begin{array}{l}\text { Dependent } \\
\text { variable }\end{array}$ & $R^{2}$ & $\begin{array}{l}\text { Independent } \\
\text { variable }\end{array}$ & $b$ & S.E. (b) & $\beta$ & $t$-statistic & $\begin{array}{c}\text { Significan } \\
\text { level }\end{array}$ \\
\hline \multirow[t]{4}{*}{ ATT } & 0.574 & Constant & 0.484 & 0.155 & & $3 \cdot 121$ & 0.002 \\
\hline & & System & -0.323 & $0 \cdot 103$ & -0.159 & $-3 \cdot 133$ & 0.002 \\
\hline & & EOU & 0.077 & 0.049 & 0.104 & 1.599 & $0 \cdot 112$ \\
\hline & & USEF & 0.532 & 0.052 & 0.651 & $10 \cdot 155$ & 0.000 \\
\hline \multirow[t]{5}{*}{ USE } & 0.365 & Constant & 3.010 & $0 \cdot 416$ & & $7 \cdot 235$ & 0.000 \\
\hline & & System & 0.366 & 0.278 & 0.084 & $1 \cdot 314$ & $0 \cdot 191$ \\
\hline & & EOU & 0.147 & 0.130 & 0.092 & $1 \cdot 129$ & 0.261 \\
\hline & & USEF & 0.669 & $0 \cdot 175$ & 0.380 & 3.829 & 0.000 \\
\hline & & ATT & 0.449 & $0 \cdot 201$ & $0 \cdot 206$ & $2 \cdot 233$ & 0.027 \\
\hline
\end{tabular}

contains the unrestricted regressions needed to carry out the hierarchical regression test of the non-significance of those causal relationships hypothesized to be non-significant. Figure 2 shows the results of the regression analyses. Most of the hypotheses were confirmed by the data. Attitude had a significant effect on usage. Perceived usefulness had a significant and strong effect on attitude. Ease of use had a smaller but also significant effect on attitude, and a strong effect on usefulness. Ease of use was significantly affected by the system, with electronic mail being perceived as easier to use than the text editor. Among the hypothesized direct effects, only the system-usefulness link was disconfirmed. Hence, aside from the differences in ease of use, the electronic mail and text editor provide similar perceived impacts on one's job performance. System and ease of use had no direct effect on usage, as hypothesized. Counter to expectation, however, usefulness had a strong direct effect on use over and above attitude. System did not have a direct effect on use, but, unexpectedly, had a small but significant effect on attitude over and above usefulness and ease of use.

Table 3 gives the point estimates and confidence intervals for the standardized

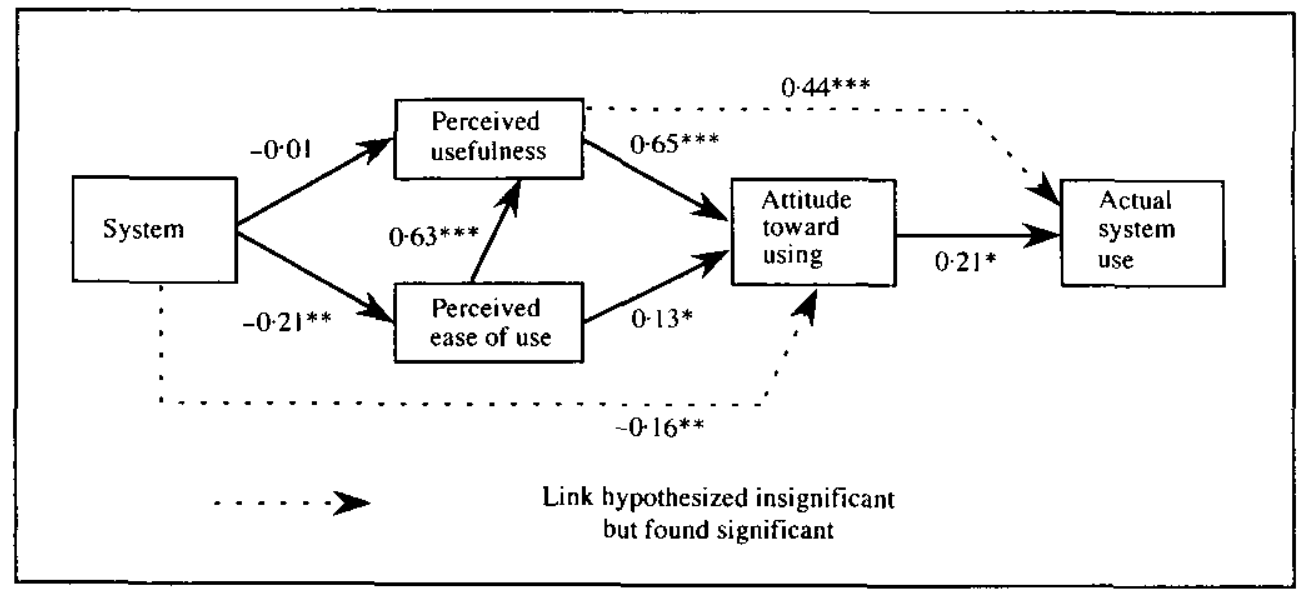

FIGURE 2. Technology acceptance model results. 
TABLE 3

TAM parameter estimates and $95 \%$ confidence intervals

\begin{tabular}{|c|c|c|c|c|c|c|}
\hline \multicolumn{2}{|c|}{ Causal link } & \multicolumn{3}{|c|}{ Point estimate } & \multicolumn{2}{|c|}{$\begin{array}{l}95 \% \text { confidence } \\
\text { interval }\end{array}$} \\
\hline $\begin{array}{l}\text { Independent } \\
\text { variable }\end{array}$ & $\begin{array}{l}\text { Dependent } \\
\text { variable }\end{array}$ & $\beta$ & S.E. & $\begin{array}{c}\text { Significance } \\
\text { level }\end{array}$ & $\begin{array}{l}\text { Lower } \\
\text { bound }\end{array}$ & $\begin{array}{l}\text { Upper } \\
\text { bound }\end{array}$ \\
\hline System & EOU & $-0 \cdot 210$ & 0.073 & 0.004 & -0.352 & -0.068 \\
\hline System & USEF & -0.014 & 0.059 & 0.812 & $-0 \cdot 129$ & $0 \cdot 101$ \\
\hline EOU & USEF & 0.630 & 0.059 & 0.000 & 0.515 & 0.745 \\
\hline System & ATT & -0.159 & $0 \cdot 051$ & 0.002 & -0.259 & -0.059 \\
\hline EOU & ATT & $0 \cdot 134$ & 0.049 & 0.043 & -0.027 & 0.235 \\
\hline USEF & ATT & 0.651 & 0.064 & $0 \cdot 000$ & 0.524 & 0.778 \\
\hline USEF & USE & 0.435 & $0 \cdot 090$ & 0.000 & 0.258 & 0.612 \\
\hline ATT & USE & 0.205 & $0 \cdot 090$ & $0 \cdot 022$ & 0.029 & $0 \cdot 381$ \\
\hline
\end{tabular}

regression coefficients. The parameters enable one to compute the relative importance of USEF and EOU in influencing USE. USEF has both a direct effect $(0 \cdot 44)$ plus an indirect effect via ATT $(0.65 \times 0.21)$. Combined, this equals 0.58 . EOU has an effect on USE through ATT: $0.13 \times 0.21$; plus an effect through USEF: $0.63 \times 0.58(0.58$ from above calculations of USEF's effect on USE). This totals 0.39 . Comparatively, therefore, USEF is about 1.5 times as important as EOU in influencing USE.

\section{Discussion}

The TAM motivational variables: attitude toward using, perceived usefulness and perceived ease of use, fully mediated the effect of system design features on usage. That is, the characteristics of the system appear to influence behavior entirely through these motivational variables and have no additional direct effect on use.

The powerful effect of usefulness on actual use, both directly, and indirectly through attitude $(0.65 * 0 \cdot 21)+0 \cdot 44=0.58$, is perhaps the most striking result. The fact that usefulness exerts more than twice as much direct influence on use than does attitude toward using (with regression coefficients of 0.44 and 0.21 for usefulness and attitude respectively) underscores the importance of the usefulness variable. In addition, usefulness exerts more than four times as much direct influence on attitude as does ease of use $(0 \cdot 65 \mathrm{vs} .0 \cdot 13)$. The direct effect of a perception on behavior over and above its indirect effect through attitude, such as the observed usefulness-use link, although inconsistent with Fishbein and Ajzen's (1975: p. 314) theory, has been observed elsewhere in psychology. An alternative model specified by Triandis (1977: p. 194), views cognitions as having a direct effect on behavioral intentions. Bagozzi (1982) found that beliefs have both a direct effect on intentions and an indirect effect through attitude. Therefore, there is some theoretical and empirical precedent for an effect of beliefs on behavior over and above their indirect effect via attitude.

Compared to usefulness, perceived ease of use has a fairly small direct effect on 
attitude primarily influencing attitude indirectly via its relatively strong effect on usefulness $(0.63 * 0.65=0.41)$. The effect of ease of use on usage operates almost entirely through its effect on usefulness, which is $0.63 *(0 \cdot 44+0.65 * 0 \cdot 21)=0.36$. Comparatively, the effect of ease of use on use through its direct effect on attitude is only $0.13 * 0.21=0.02$. Why does ease of use operate primarily through usefulness? The usefulness construct may reflect considerations of both the "benefits" and the "costs" of using the target system (e.g. Einhorn \& Hogarth, 1981; Johnson \& Payne, 1985). Ease of use (or more appropriately its opposite, effort of use) may be seen as part of the cost of using the system from the user's perspective. One possible direction for future research would be to attempt to define and measure the "benefits" of use in a particular context.

The small but significant direct influence of system characteristics on attitude toward using $(-0 \cdot 16)$ suggests that perceived usefulness and perceived ease of use may not be the only beliefs mediating between system and attitude. This leads us to consider possible beliefs that should be added to the model. The previous discussion has emphasized the importance of perceived usefulness, arguing that ease of use operates through this variable. Thus, the model views computer usage behavior to be largely extrinsically motivated, being driven by concern over performance gains and associated rewards. Malone (1981) points out that intrinsic motives also play an important role in determining usage of computer systems. That is, people use systems in part because they enjoy the process of using them per se, not just because they are extrinsically rewarded for the performance impacts of usage. Intrinsic motivation may be one mechanism underlying the observed direct effect of system characteristics on attitude toward using. From this perspective, an individual's affect toward using a given system is jointly determined by the extrinsic and intrinsic rewards of using the system. Future research is needed to address the relative roles of extrinsic and intrinsic motivation in user acceptance.

Future research should consider the role of additional variables within TAM. The two systems examined in the present research were available for voluntary use by employees. In situations where people are required to use a given system due to management strictures, the model would need to be extended. Such users would be motivated to use the system not necessarily because they have positive attitudes, or believe it to be easy to use or useful, but instead because they feel impelled to use it by management. Such a motivational construct may well be similar in spirit to Ajzen and Fishbein's (1980) "subjective norm", which captures the individuals' belief that relevant others want them to perform a given behavior and their motivation to comply with such desires. Other variables that could be examined include system familiarity or experience, top management support, user involvement, task characteristics (such as complexity) and a more finely grained representation of design features than the electronic mail vs. text editor comparison addressed here. All of these latter variables come under the rubric of external variables in Ajzen and Fishbein's (1980) model, and should therefore operate through attitudes or subjective norms. In addition, future research should attempt to replicate these findings using separate instruments for motivational variables and usage to rule out response biases and to see the extent to which these results generalize to other systems and user populations.

The present findings have implications for improving user acceptance. Many 
designers believe that the key barrier to user acceptance is the lack of user friendliness of current systems, and that adding user interfaces that increase usability is the key to success (e.g. Branscomb \& Thomas, 1985). Yet the present results indicate that, although ease of use is clearly important, the usefulness of the system is even more important and should not be overlooked. Users may be willing to tolerate a difficult interface in order to access functionality that helps them on their job, while no amount of ease of use can compensate for a system that doesn't do a useful task. Diagnostic measures such as those used in TAM should help practitioners identify and evaluate strategies for enhancing user acceptance.

The technology acceptance model has promise as a practical tool for early user acceptance testing. Given the large investments at stake when developing new systems, it is desirable to forecast user acceptance as early as possible in the design process (Gould et al., 1991; Rosson, Maass \& Kellogg, 1987). Early in design: (1) many key decisions are made about the design of the system, (2) only a small fraction of development costs have been incurred and (3) greatest flexibility exists to modify the design. User acceptance tests performed early in design, if sufficiently predictive of future user acceptance, could reduce the risk of user rejection by enabling designers to better screen, prioritize and refine application ideas. Although early testing is widely used and encouraged by practicing designers, it is not known how well measures captured early in design reflect the level of user acceptance that would actually occur after an information system is implemented in the workplace. In practice, early user testing occurs at two main points in the design process. The typical approach is to build a prototype of the application, have representative potential users interact with it, measure various performance criteria and subjective evaluations, and iteratively refine the design (e.g. Gould et al., 1991; Rosson, Maass \& Kellogg, 1987). Some designers have attempted to push user testing even earlier in the design process by having prospective users provide assessments of video mockups of applications (e.g. Apple Computer, 1988; Harrison et al., 1989; Henderson, 1989; Mantei \& Teorey, 1988; Vertelney, 1989). Research is needed on how well measurements taken in response to prototypes or video mockups predict actual user acceptance in the workplace. TAM provides a foundation for further research on why users accept or reject information technology and how to improve user acceptance by judicious choice of system design features.

The author wishes to thank Massachusetts Institute of Technology, IBM Canada Ltd, and The Univeristy of Michigan for financial support of this research, and John Carroll, John Henderson, Tom Malone and three anonymous reviewers for helpful comments on earlier versions of this paper.

\section{References}

AJzen, I. \& Fishbein, M. (1977). Attitude-behavior relations: a theoretical analysis and review of empirical research. Psychological Bulletin, 84, 888-918.

Ajzen, I. \& Fishbein, M. (1980). Understanding Attitudes and Predicting Social Behavior. Englewood Cliffs, NJ: Prentice-Hall.

Apple Computer (1988). Knowledge Navigator, video. 
BAgozzı, R. P. (1982). A field investigation of causal relations among cognitions, affect, intentions and behavior. Journal of Marketing Research, 19, 562-584.

BAGOzzı, R. P. (1984). Expectancy-value attitude models: an analysis of critical measurement issues. International Journal of Research in Marketing, 1, 295-310.

Branscomb, L. M. \& Thomas, J. C. (1985). Ease of use: a system design challenge. IBM Systems Journal, 23, 224-235.

Davis, F. D. (1989). Perceived usefulness, perceived ease of use, and user acceptance of information technology. MIS Quarterly, 13, 319-340.

Duncan, O. D. (1975). Introduction to Structural Equation Models. New York: Academic Press.

EInhorn, H. J. \& Hogarth, R. M. (1981). Behavioral decision theory: processes of judgment and choice. Annual Review of Psychology, 32, 53-88.

Einhorn, H. J., Kleinmuntz, D. N. \& Kleinmuntz, B. (1979). Linear regression and process-tracing models of judgment. Psychological Review, 86, 465-485.

FAz1O, R. H. \& ZANNA, M. P. (1981). Direct experience and attitude-behavior consistency. Advances in Experimental Social Psychology, 14, 161-202.

Fishbein, M. \& AJZEN, I. (1975). Belief, Attitude, Intention and Behavior: An Introduction to Theory and Research. Reading, MA: Addison-Wesley.

GinZBERG, M. J. (1981). Early diagnosis of MIS implementation failure: promising results and unanswered questions. Management Science, 27, 459-478.

Goodwin, N. C. (1987). Functionality and usability. Communciations of the ACM, 30, 229-233.

Gould, J. D., BoIEs, S. J. \& LewIS, C. (1991). Making usable, useful, productivity-enhancing computer applications. Communciations of the ACM, 34, 74-85.

Goslar, M. D. (1986). Capability criteria for marketing decision support systems. Journal of Management Information Systems, 3, 81-95.

Harrison, S., Minneman, S., Stults, B. \& Weber, K. (1989). Video: a design medium. SIGCHI Bulletin, 21, 62-66.

Hartley, C., Brecht, M., Pagerly, P., Weeks, G., Chapanis, A. \& Hoecker, D. (1977). Subjective time estimates of work tasks by office workers. Journal of Occupational Psychology, 50, 23-36.

Hauser, J. R. \& Shugan, S. M. (1980). Intensity measures of consumer preference. Operations Research, 28, 279-320.

Henderson, A. (1989). Video and design. SIGCHI Bulletin, 21, 104-197.

Hill, T., SMITH, N. D. \& MANN, M. F. (1987). Role of efficacy expectations in predicting the decision to use advanced technologies: the case of computers. Journal of Applied Psychology, 72, 307-313.

Johnson, E. J. \& PAyne, J. W. (1985). Effort and accuracy in choice. Management Science, 31, 395-414.

Klein, G. \& BeCK, P. O. (1987). A decision aid for selecting among information system alternatives. MIS Quarterly, 11, 177-186.

LAND, K. C. (1973). Identification, parameter estimation, and hypothesis testing in recursive sociological models. In A. S. Goldberger \& O. D. Duncan, Eds. Structural Equation Models in the Social Sciences, pp. 19-49, New York: Seminar Press.

Malone, T. W. (1981). Toward a theory of intrinsically motivating instruction. Cognitive Science, 4, 333-369.

Mantei, M. M. \& Teorey, T. J. (1988). Cost/benefit analysis for incorporating human factors in the software lifecycle. Communications of the ACM, 31, 428-439.

McCarroll, T. (1991). What new age? Time, 138, 12 August, 44-46.

Nickerson, R. S. (1981). Why interactive computer systems are sometimes not used by people who might benefit from them. International Journal of Man-Machine Studies, 15, 469-483.

Reimann, B. C. \& Waren, A. D. (1985). User-oriented criteria for the selection of DSS software. Communciations of the ACM, 28, 166-179.

Robey, D. (1979). User attitudes and management information system use. Academy of Management Journal, 22, 527-538. 
Rosson, M. B., MaAss, S. \& Kellogg, W. A. (1987). Designing for designers: analysis of design practice in the real world. In J. M. CARROL \& P. P. TANNER, Eds, CHI + GI 1987 Conference Proceedings, Human Factors in Computing Systems and Graphics Interface, pp. 137-141, Toronto, 5-9 April.

SCHMIDT, F. L. (1973). Implications of a measurement problem for expectancy theory research. Organizational Behavior and Human Performance, 10, 243-251.

Shoemaker, P. J. H. \& Waid, C. C. (1982). An experimental comparison of different approaches to determining weights in additive utility models. Management Science, 28, $182-196$.

Stahi., M. J. \& Harrell, A. M. (1981). Modeling effort decisions with behavioral decision theory: toward an individual differences model of expectancy theory. Organizational Behavior and Human Performance, 27, 303-325.

Swanson, E. B. (1982). Measuring user attitudes in MIS research: a review. $O M E G A, 10$, $157-165$.

Triandis, H. C. (1977). Interpersonal behavior. Monterey, CA: Brooks/Cole.

Vertelney, L. (1989). Using video to prototype user interfaces. SIGCHI Bulletin, 21, 57-61.

\section{Appendix}

PERCEIVED USEFULNESS OF ELECTRONIC MAIL

$\begin{array}{ccc}\text { Strongly } & & \text { Strongly } \\ \text { agree } & \text { Neutral } & \text { disagree }\end{array}$

1. Using electronic mail improves the quality of $1 \begin{array}{lllllll}1 & 2 & 3 & 4 & 5 & 6 & 7\end{array}$ the work I do.

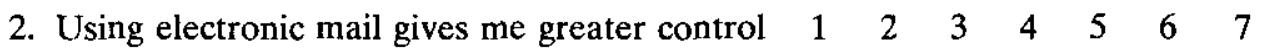
over my work.

$\begin{array}{llllllll}\text { 3. E.lectronic mail enables me to accomplish } & 1 & 2 & 3 & 4 & 5 & 6 & 7\end{array}$ tasks more quickly.

4. Electronic mail supports critical aspects of my $1 \begin{array}{lllllll}1 & 2 & 3 & 4 & 5 & 6 & 7\end{array}$ job.

5. Using electronic mail increases my productivity.

6. Using electronic mail improves my job performance.

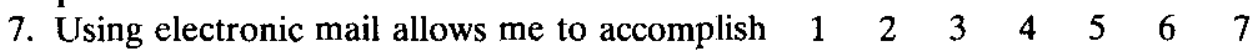
more work than would otherwise be possible.

$\begin{array}{llllllll}\text { 8. Using electronic mail enhances my } & 1 & 2 & 3 & 4 & 5 & 6 & 7\end{array}$ effectiveness on the job.

9. Using electronic mail makes it easier to do my $1 \begin{array}{lllllll}1 & 2 & 3 & 4 & 5 & 6 & 7\end{array}$ job.

10. Overall, I find the electronic mail system $\quad \begin{array}{llllllll}1 & 2 & 3 & 4 & 5 & 6 & 7\end{array}$ useful in my job. 
PERCEIVED EASE OF USE OF ELECTRONIC MAIL

1. I find the electronic mail system cumbersome
Strongly agree
Strongly

$\begin{array}{lllllll}1 & 2 & 3 & 4 & 5 & 6 & 7\end{array}$ to use.

2. Learning to operate the electronic mail system $\begin{array}{llllllll}1 & 2 & 3 & 4 & 5 & 6 & 7\end{array}$ is easy for me.

3. Interacting with the electronic mail system is $\begin{array}{llllllll}1 & 2 & 3 & 4 & 5 & 6 & 7\end{array}$ often frustrating.

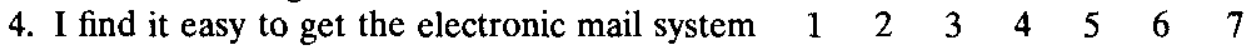
to do what I want it to do.

5. The electronic mail system is rigid and inflexible to interact with.

6. It is easy for me to remember how to perform tasks using the electronic mail system.

7. Interacting with the electronic mail system requires a lot of mental effort.

$\begin{array}{llllllll}\text { 8. My interaction with the electronic mail system } & 1 & 2 & 3 & 4 & 5 & 6 & 7\end{array}$ is clear and understandable.

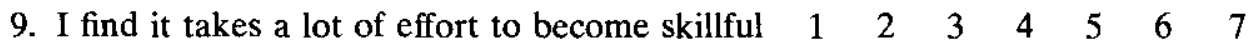
at using electronic mail.

$\begin{array}{llllllll}\text { 10. Overall, I find the electronic mail system easy } & 1 & 2 & 3 & 4 & 5 & 6 & 7\end{array}$ to use. 